\title{
SYNTHESIS
}

Synthesis

ISSN: 0328-1205

ISSN: 1851-779X

revistasynthesis@gmail.com

Universidad Nacional de La Plata

Argentina

\section{Las cartografías del tiempo en la Pítica IX de Píndaro}

\author{
Hamamé, Graciela N. \\ Las cartografías del tiempo en la Pítica IX de Píndaro \\ Synthesis, vol. 26, núm. 2, 2019 \\ Universidad Nacional de La Plata, Argentina \\ Disponible en: http://www.redalyc.org/articulo.oa?id=84662943002 \\ DOI: https://doi.org/10.24215/1851779Xe059
}

Esta obra está bajo una Licencia Creative Commons Atribución-NoComercial-Compartirlgual 4.0 Internacional. 
Artículos

\title{
Las cartografías del tiempo en la Pitica IX de Píndaro
}

\author{
The Cartographies of Time in Píndar's Pythian IX \\ Graciela N. Hamamé \\ Universidad Nacional de La Plata, Argentina \\ gracielahamame@gmail.com
}

DOI: https://doi.org/10.24215/1851779Xe059

Redalyc: http://www.redalyc.org/articulo.oa?id=84662943002

Recepción: 10 Agosto 2019

Aprobación: 28 Agosto 2019

\section{Resumen:}

Este trabajo pretende un acercamiento a la poética de Píndaro a partir del análisis de las categorías de espacio y tiempo en la Pítica IX. La oda se remonta al 474 a. C., momento en que el poeta alcanza su madurez artística y constituye uno de los epinicios más extensos entre las composiciones conservadas del autor. Tiempo y espacio de la performance, en constante diálogo con las coordenadas de la ocasión del epinicio y de las narraciones míticas, revelan la maestría de uno de los más exquisitos poetas líricos de la Antigüedad.

Palabras clave: Píndaro, Pitica IX, Tiempo, Espacio.

\section{AbstraCt:}

This work intends an approach to the poetics of Pindar from the analysis of the categories of space and time in his Pythian IX. The ode dates back to 474 a. C., at which point the poet reaches his artistic maturity and constitutes one of the most extensive epinices among the author's preserved compositions. Time and space of the performance, in constant dialogue with the coordinates of the occasion of the epinice and the mythical narratives, reveal the mastery of one of the most exquisite lyric poets of Antiquity.

Keywords: Pindar, Pythian IX, Time, Space.

A partir del contacto con el trabajo de Lamari sobre Fenicias de Eurípides, ${ }^{1}$ se indagó la propuesta de Irene de Jong que consiste en aplicar los estudios narratológicos a obras literarias que no pertenecen al género narrativo per se, pero que albergan secciones narrativas. En primera instancia, y con el modelo antes mencionado, nos abocamos al trabajo con el género trágico. A modo de continuidad del desafío que significó el análisis de las secciones corales de la tragedia, surgió la inquietud de ensayar el abordaje de las odas corales integrando este innovador enfoque a la metodología con la que venimos trabajando desde nuestra formación en las cátedras del área griego de la Facultad de Humanidades y Cs. de la Educación de la UNLP.

Comenzamos por un exhaustivo análisis filológico al servicio de la consecuente interpretación literaria y, tomando como bibliografía de base, en primera instancia, las enseñanzas y los trabajos de la Prof. Carmen Verde Castro, especialmente el artículo publicado en 2009, y los capítulos dedicados a Píndaro de los tres tomos que lleva editados de Jong hasta el momento, a cargo de Pfeiffer (2004), Nünlist (2007) y Currie (2012) respectivamente, nos propusimos arribar a una interpretación más abarcadora, a nuestro entender, de la Pitica IX del poeta tebano. ${ }^{2}$

El propósito de la composición que denominamos epinicio no es relatar una competencia sino celebrar la victoria obtenida por el atleta. La poesía de Píndaro no pertenece al género narrativo, sino que introduce unidades narrativas con otro propósito. ${ }^{3}$ Contrariamente a lo que el destinatario actual espera, el poeta no nos refiere de qué manera el vencedor consiguió el triunfo. La oda no involucra un reporte de la competencia; el objetivo primordial radica en recordar datos que definen la victoria celebrada: el vencedor, el nombre del padre o familia, el lugar de origen, su regreso triunfal y la disciplina en la que compitió pero, para otorgar entidad física exclusiva a la hazaña referida, resultan ineludibles las coordenadas de espacio y tiempo. ${ }^{4}$ De esta 
manera, la obra cumple un deber impostergable de difusión en la comunidad. Sin embargo, el compromiso entrañable de Píndaro aspira a enlazar estos datos de la simple información con "un planteo más generoso, donde el éxito del momento se comprenda como el más reciente -y no el último- en la historia de un linaje escogido y predestinado" (Verde Castro, 2009, pp. 169-170). Para enaltecer la gloria y fama del vencedor, se asocia su desempeño a acciones protagonizadas por personajes míticos. Por ello, aunque los epinicios no pertenecen al género narrativo, la mayoría de estas composiciones incluyen secciones narrativas. De aquí que toda oda de victoria deviene un texto híbrido, en el que es posible diferenciar distintos componentes: la narrativa, la alabanza del vencedor, de su tierra, de su familia, gnómai o sentencias, invocaciones y plegarias. ${ }^{5}$

La datación de la Pítica IX se remonta al 474 a. C., momento en que el compositor alcanza su madurez artística. Se considera que la performance tuvo lugar en Cirene (actual Libia, en África), ciudad del vencedor Telesícrates.

El epinicio, uno de los más extensos, se estructura formalmente en cinco tríadas (A: 1-25; B: 26-49; Г: 50-75; $\Delta$ : 76-100; E: 101-125). Procederemos al análisis de cada una de ellas con el fin de desentrañar el juego de relaciones que nos permitan arribar a conclusiones que iluminen la interpretación de la obra.

La estrofa A comienza con el verbo $\dot{\varepsilon} \theta \hat{\varepsilon} \lambda \omega$ en una enérgica $1^{\circ}$ persona de Indicativo que, con el infinitivo objetivo $\gamma \varepsilon \gamma \omega \nu \varepsilon \tilde{\imath}$ declara, abiertamente, el carácter de epinicio del poema y el tiempo presente de la celebración del triunfo. En las cuatro primeras líneas, el poeta expone de manera concisa el carácter de la obra, la ocasión, el lugar del certamen, el vencedor y su ciudad de procedencia:

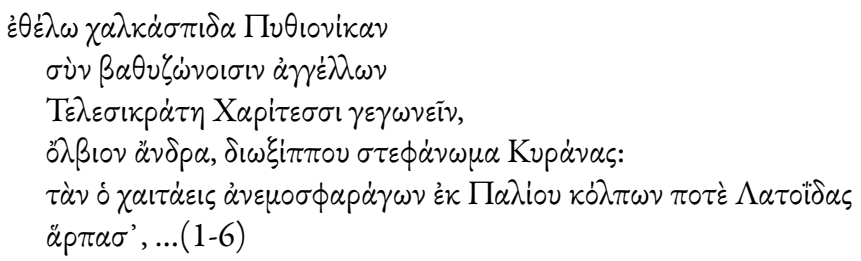

Quiero proclamar al vencedor en Delfos, el que porta escudo de bronce, anunciando junto con las Gracias de ceñida cintura a Telesícrates, varón dichoso, corona de flores de Cirene, conductora de caballos; [5] a la que el hijo de Leto de larga cabellera, alguna vez, desde las honduras del Pelión que hacen ecos a los vientos, raptó; ... ${ }^{6}$

La única referencia al tipo de competencia está dado por medio de una sinécdoque, $\chi \alpha \lambda \kappa \dot{\alpha} \sigma \pi\llcorner\delta \alpha$ (v. 1), la cual destaca, de este modo, el escudo de bronce, en tanto símbolo prominente de la armadura completa. ${ }^{7} \mathrm{La}$

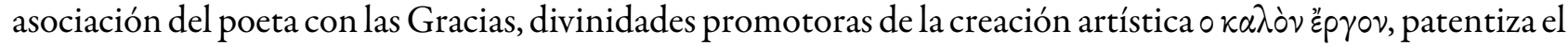
trabajo que Píndaro se propone. Cirene, la ciudad del vencedor, culmina el verso 4; asimismo, el adjetivo que se le atribuye - $\delta \iota \omega \xi i \pi \tau \circ \nu$ - como el pronombre $\tau \alpha \dot{\nu} \nu$ que encabeza el verso 5 , marcan la dualidad de significación con que Kvpáva transitará la oda, ya que no la retoma como ciudad, sino como la ninfa del mito que el poeta incluye tempranamente en el poema. Este primer relato desarrolla la historia de amor de la que participan dos divinidades, y establece el origen célebre de la ciudad de Cirene y de sus dioses protectores. El pronombre $\tau \dot{\alpha} \nu$, además, vehiculiza el pasaje de la actualidad de la ocasión del canto, manifestada en el tiempo presente, hacia el pasado prestigioso del mito por medio de aoristos precisos inequívocos; del lugar real de la performance, hacia el espacio legendario. El adverbio $\tau \circ \tau \varepsilon \dot{\varepsilon}$ ubicado en la misma línea, acompaña e induce al receptor del canto (el narratario) a internarse en el relato secundario del mito, en un tiempo impreciso y remoto. A diferencia de otras producciones, en este caso, el poeta elige no explayarse en la estampa del vencedor -por ahora-, y adelanta el mito. La apertura y el cierre del verso en cuestión destacan las figuras centrales de la historia: $\tau \dot{\alpha} \nu=$ Cirene, $\Lambda \alpha \tau o i ̈ \delta \alpha \varsigma=$ Apolo; objeto y sujeto del rapto son explicitados en una especie de adelanto de la narración que se extenderá hasta el verso 25 , a modo de esbozo esquemático de aquello que se desarrollará a partir de la segunda tríada. Entre los versos 6 y 8 , Píndaro diseña la región en la que Apolo aspira consumar su deseo y erigir a su amada como soberana de una nueva ciudad. El artista introduce la teoría de la división del mundo y ubica la tierra sobre la que reinará la ninfa en Libia. Se observa un primer desplazamiento tanto en el 
plano temporal como en la perspectiva espacial cuando, desde el presente de la celebración en Cirene, el mito nos interna en un pasado en el que los personajes se desplazan desde Tesalia (sitio donde el dios encuentra a la joven) hacia Libia, en el tercer continente, junto con Europa y Asia. ${ }^{8}$

En $\mathrm{A}^{\prime}$ Afrodita se muestra favorable a las pretensiones del dios y dispone la boda entre Febo y la "agreste doncella”. En el verso 13 se menciona por primera vez el motivo de las bodas, el cual reaparecerá en los versos 66 y 114. La relación entre estas ocurrencias en el epinicio establece las reiteraciones como un leitmotiv de la composición.

Entre los versos 14 y 18 se presenta la genealogía de Cirene. El relato se interna en un pasado más lejano

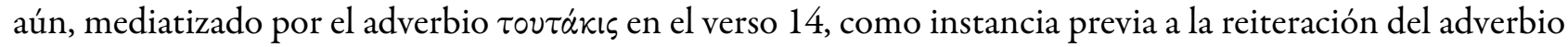
$\pi \circ \tau \varepsilon ́$ dentro de la relativa que despliega la genealogía de Hipseo, en el verso 15. La estructura sintáctica refleja diversos planos de subordinación en los que la perspectiva temporal hacia el pasado o analepsis se reafirma con el uso de los adverbios temporales. ${ }^{9}$ Si bien las narraciones de Píndaro siguen en su mayoría un orden cronológico, pueden aparecer, como en este caso, ciertas instancias de anacronía a las que el poeta recurre para proporcionar un sustento lógico o fáctico a algún elemento de la historia (Nünlist, 2012, p. 245). Presentar a la ninfa y su reconocido linaje otorga prestigio a la ciudad de procedencia del vencedor, a la vez que exterioriza una primera vinculación entre los dos continentes involucrados en el poema.

El Epodo A se detiene en la caracterización de la joven por medio de maravillosas imágenes visuales con las que se recalcan las actividades que la diferencian del resto de las muchachas. Una sola oración compuesta por dos proposiciones coordinadas resulta suficiente para realzar el perfil de la joven en contraposición a las tareas del común de las doncellas. En contraste con el aoristo que especifica aquello que Cirene no hace [ö̈ $\theta$ ' $\varepsilon \phi \lambda \eta \sigma \varepsilon v$, v. 18], el poeta se vale del pretérito imperfecto que domina la segunda coordinada, expandido en participios activos de presente, para explayarse en la descripción de la ninfa. Su figura se asemeja más a la de una virgen destinada a Artemis que a la de una joven novia, rasgos que han provocado la admiración de Apolo. El tiempo verbal dominante resulta el propio de la descripción. El epodo construye el nexo que facilita el regreso hacia lo primigenio, hasta el punto cero del relato central. Esta caracterización de Cirene aflorará en el primer contacto visual que Apolo establezca con ella y que proporcionará el motivo de la estrofa siguiente.

Con la estrofa $\mathbf{B}$ comienza el despliegue del mito, donde se narran las acciones previas que condujeron a la unión marital entre los dos personajes. Nuevamente, la presencia de un $\pi \circ \tau \varepsilon ́$ remite al pasado prodigioso del relato. El empleo variado de epítetos al estilo homérico y la abundancia de imágenes tiñen el poema de un tono lírico original y distintivo.

Apolo sorprendió a la doncella mientras ella luchaba sola contra un león; inmediatamente el dios se

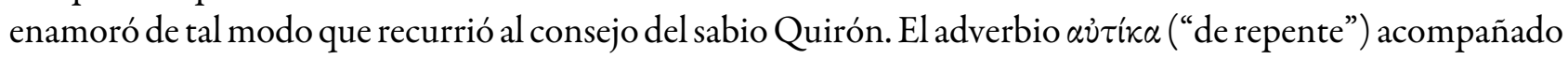
del coordinante $\delta^{\prime}$ da cuenta de la inmediatez y de lo repentino del sentimiento de Febo (v. 29). Entre los versos 31 y 37, a partir de un discurso directo, en un pasaje de belleza sin igual, el espectador accede a las emociones de Apolo sin mediación alguna, dios totalmente subyugado y altamente vulnerable. Este recurso no sólo torna más vívidos los sentimientos de la divinidad sino que sume al público en el tiempo mítico originario. Sus palabras se concentran en la tercera persona, describe las acciones de la joven a partir de la subjetividad de su mirada iluminada de admiración y encantamiento, al tiempo que expone sus emociones y relega la primera persona:

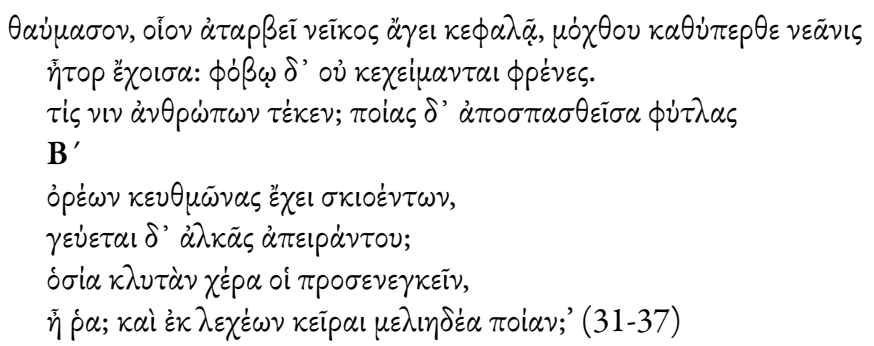


mira con asombro el temperamento de una mujer y su gran fuerza. ¿Qué pelea con audaz cabeza lleva adelante una doncella con un corazón por encima de la dificultad! Con el temor los sentidos no se conducen a través de una tormenta. ¿Quién entre los hombres la engendró? ¿De cuál linaje arrancada

B

habita las cañadas de las sombrías montañas [35] y goza de un coraje sin límites?

¿Acaso está permitido por la ley divina poner la mano sobre ella, y de los lechos cortar una flor dulce como la miel?

El desplazamiento temporal desde el presente de la ocasión $[\dot{\varepsilon} \theta \varepsilon \lambda \omega, \mathrm{v} .1]$ hacia el pasado mítico representado por aoristos [ $\kappa i ́ \chi \varepsilon$, v. 26], vuelve a las inflexiones verbales asociadas al tiempo presente a través del estilo directo; lo que el público escucha es un presente que fácilmente se asocia a su propia actualidad. Presente de la performance y pasado primigenio del relato se confunden en un mismo tiempo verbal que introduce al espectador en los más profundos recovecos de un tiempo maravilloso. En este punto se destaca la gradación en el uso de las formas verbales y los contextos donde aparecen, como el imperativo de aoristo [ $\theta \alpha \dot{v} \mu \alpha \sigma \circ v, \mathrm{v}$. 31] con el que se apela al receptor del discurso directo o la atemporalidad de una gnóme (v. 32), para alcanzar la presencia de ese pasado extraordinario tan distante. De esta manera, el espectador se traslada naturalmente desde el pretérito hacia un presente que no indica la ocasión del canto sino la vigencia de un pasado aún anterior.

No tarda en llegar la respuesta, en la que el consejero, tal vez con temor de que un impulso domine a Apolo, subraya la necesidad de la persuasión y de la privacidad de los amores divinos (vv. 39-41). ${ }^{10}$ Por ello, a partir del verso 42 explica la razón para recordárselo, ya que, preso de una "pasión amable" (v.43), el hijo de Leto parece haber olvidado su carácter divino y omnisciente.

En consecuencia, con un futuro de indicativo, en el comienzo de la estrofa G (v. 51) el centauro anuncia que comunicará la profecía. El discurso directo del sabio expone a Apolo como sujeto de la situación y apela a la divinidad, en la segunda persona gramatical, para que se haga cargo de la misma. Con $v \tilde{v} \delta$ 'en el verso 55 se establece una gradación dentro de la prolepsis que aporta el vaticinio y se revela el futuro más cercano en relación al recibimiento de Libia, confirmando y especificando la nueva sede decretada para la consumación de los amores del dios. Explica de qué modo Libia recibirá a la ninfa (vv. 55-57) y cómo "al momento" [a jíḱ, v. 57] le otorgará una porción de tierra rica en plantas con toda clase de frutos y animales donde ejercer su dominio. El adverbio reafirma el punto de partida para la proyección hacia un futuro más lejano, encaminado de manera gradual hasta alcanzar su instancia culminante cuando en $\mathbf{G}^{\prime}$ predice el nacimiento de Aristeo,

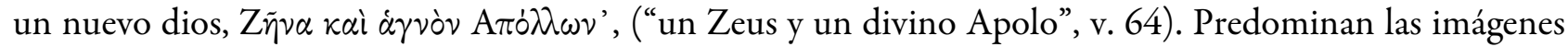
visuales que ofrecen una especie de representación pictórica de escenas. La participación de las Horas y Gaia en la crianza del recién nacido convalida su divinidad y lo establece como dios protector de los campos y los seres que los habitan. De esta manera culmina, en el verso 65, el discurso directo del centauro. La profecía de Quirón concede carácter divino al origen de la ciudad de Cirene, cuna del vencedor. La línea 66 retoma la idea del matrimonio y su $\tau \varepsilon p \pi \nu \dot{\alpha} \nu \tau \varepsilon \lambda \varepsilon \nu \tau \dot{\alpha} \nu$ ("gozosa concreción”). La utilización del pretérito imperfecto de indicativo permite salir del tono profético de manera gradual.

El Epodo G comienza con una sentencia que resalta las virtudes de los dioses como impulsores de acción,

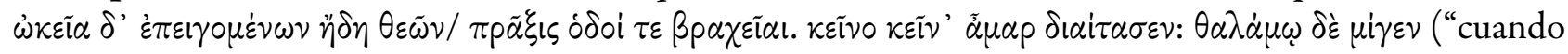
ya los dioses se apresuran, rápida resulta la acción, y cortos los caminos", vv. 67-68). De esta manera se cierra la instancia de prolepsis y el poeta vuelve a valerse del aoristo para concluir el mito con la consumación de la unión y destacando a la ciudad por la fama alcanzada a causa de sus competiciones. En el verso 71 la frase

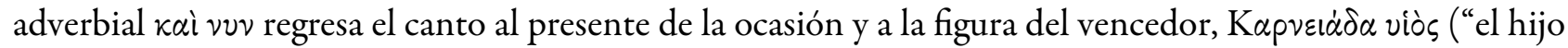
de Carnéades", vv. 71-72), quien unido a la fortuna [ $\sigma \nu v \varepsilon ́ \mu \xi \varepsilon]$, como se asociaron en el mito Cirene y Apolo

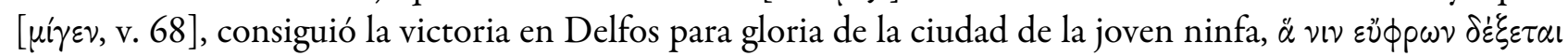

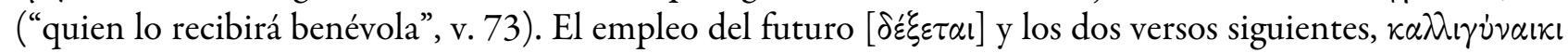
$\pi \dot{\alpha} \tau p \alpha / \delta \delta^{\prime} \xi \alpha \nu$ i $\mu \varepsilon \rho \tau \dot{\alpha} \nu \dot{\alpha} \gamma \alpha \gamma \dot{o} \nu \tau$ ” $\dot{\alpha} \pi \grave{o} \Delta \varepsilon \lambda \phi \tilde{\omega} \nu$ ("cuando a la patria rica en bellas mujeres traiga desde Delfos la 
fama deseada”, vv. 74-75), dejan en evidencia que Telesícrates todavía no ha llegado a su tierra. ${ }^{11}$ Kvpáva vuelve a vestirse de ciudad y cierra el circuito, a modo de composición en anillo, iniciado en la línea 4.

En la tríada $\mathrm{D}$, una vez concluido el ciclo mítico que había dejado en suspenso la figura del vencedor, el poeta reanuda su encomio. Parte de una gnóme en referencia a la labor del poeta, con la que justifica una selección de las principales victorias que Telesícrates ha obtenido. ${ }^{12}$ Donde hay abundancia de acciones para alabar -sostiene- la sabiduría del poeta reside en expresar con arte y elegancia, la selección correcta. Entre los versos 79 y 88, Píndaro enaltece a su propia ciudad, Tebas, y a los héroes asociados a ella. El poeta inicia con la mención de Yolao, que le permite introducir, brevemente, una referencia al nacimiento de Heracles y del padre de Yolao, Ificles. El compositor los celebrará con su canto y, de esta manera, otorgará fama y gloria a Telesícrates y a sí mismo, cuando por el poema conceda gloria a su ciudad natal. Los versos 89-90 reavivan el comienzo del epinicio; el poeta espera que las Gracias no lo abandonen para proclamar, ya en el epodo, la aretalogía del vencedor, la cual se extiende hasta las primeras líneas de la última tríada:

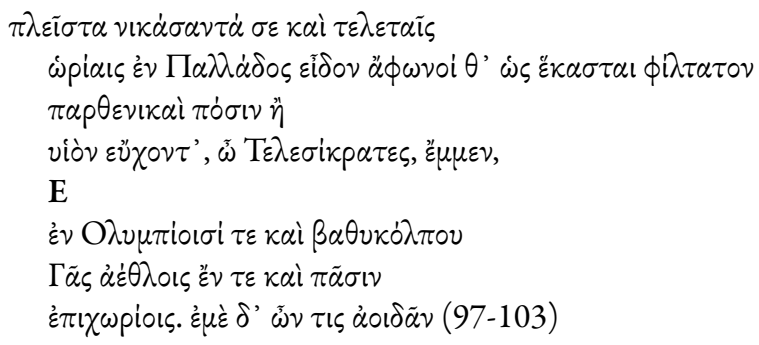

También vi que triunfaste en las fiestas anuales de Palas, y cómo cada una de las mujeres, privadas de voz, [100] rogaban ioh Telesícrates! que fueras su amadísimo esposo o su hijo, y también en los Juegos olímpicos y en los de la Tierra de pliegue profundo y en todos los de tu tierra.

El par estrófico E-E' inicia con el compromiso renovado del poeta con su creación (v. 103-104); debe pagar su deuda de alabanza al vencedor y para ello se vuelve necesario ennoblecer la reputación de sus antepasados. De esta forma, se introduce la segunda historia de amor que pertenece a la comunidad de Libia e involucra a un ancestro del vencedor, historia que, seguramente, la propia familia ha comunicado al compositor a la hora de contratarlo. Nuevamente un pronombre oío (v. 105) marcará la transición del presente al pasado mítico dando lugar a la historia de Alexidamo y la hija de Anteo. Esta narración de índole local incluye, como modelo de acción de Anteo, el mito de Dánao y el casamiento de sus hijas. El verso 110, con la imagen de cortar el fruto de la virginidad de la doncella pretendida, recuerda el verso 37 tanto en el nivel semántico como en el sintáctico.

Como sucedió con el mito de Cirene, los distintos planos temporales del relato van a estar presentes, no obstante de otro modo. En el primer relato mítico, el poeta nos remontaba al pasado remoto con la inclusión de discursos directos que, a través del presente de indicativo, nos retrotraían al pretérito más distante. En esta última narración, el segundo plano temporal del pasado se introduce a partir de un segundo nivel sintáctico, por medio de una completiva objetiva dependiente del verbo ảkov́w:

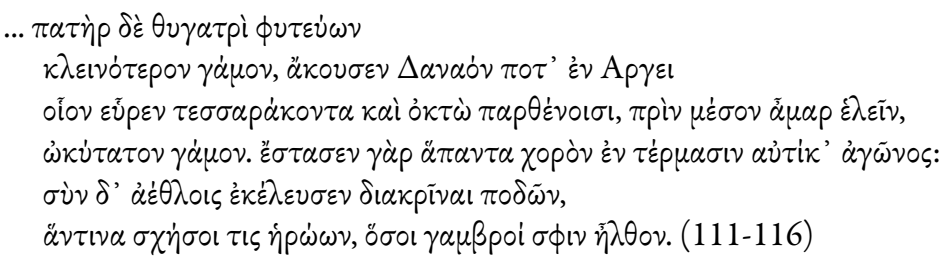

Sin embargo el padre que para la hija tenía sembrada la semilla de un más glorioso matrimonio, escuchó cómo alguna vez Dánao, en Argos, encontró para sus cuarenta y ocho hijas, antes de ganar la mitad del día, el más rápido casamiento; pues colocó todo el conjunto [de hijas] a la vez en el final del lugar del certamen, y ofreció determinar con carreras a cuál de ellas conseguiría cada uno de los héroes cuantos llegaron a él como prometidos. 
La completiva objetiva de ảkov́w ofrece el marco sintáctico para introducir rápidamente el mito de Dánao. A su vez, acentuando el paralelismo con el primer relato, tal como se adelantara oportunamente, en los versos 112 y 114 se reitera el término $\gamma$ áuov, leitmotiv que reviste, en todas las apariciones, la misma función sintáctica, es decir, como objeto de las pretensiones de los protagonistas de cada historia. En los tres casos la unión marital representa el logro del objetivo que cada uno de los personajes ha perseguido en las respectivas historias.

El regreso a la prehistoria de Alexidamo ocurre en el inicio del Epodo E por medio del adverbio ov̈ $\tau \omega$. Anteo propone dirimir la contienda de pretendientes para su hija por medio de un certamen en el que Alexidamo resulta victorioso. Esta segunda sección narrativa enaltece aún más el sentido de la competencia. A modo de composición en anillo, nuevamente se cierra otro círculo, esta vez, más amplio. En los últimos tres versos se retoman los conceptos destacados en las primeras líneas de la oda: las coronas, las cuales, asociadas desde un comienzo a Telesícrates y al poema mismo, como medio para otorgar gloria al vencedor y su tierra, tienen eco en las alas de la victoria y las coronas que la tropa de jinetes nómades arroja al paso de Alexidamo. De este modo, queda establecido la analogía entre el campeón cirenense y su antepasado más célebre. Ambos resultan hitos incuestionables en la tradición de la ciudad de Cirene de la mano de un valioso triunfo en sendas competiciones: en el pasado primigenio de la ciudad, Alexidamo, ancestro ilustre, vencedor en la carrera que le concedió la mano de la hija de Anteo; por su parte, actualizando la fama de la ciudad de Cirene, Telesícrates, quien suma a victorias locales previas, el triunfo en la carrera con armas en los juegos Pitios, motivo del canto del presente de la performance.

Para finalizar, resulta insoslayable una consideración acerca de la figura del narrador. El poeta opera como un narrador primario, encargado de introducir las tres perspectivas narrativas. Dentro de la primera y principal que tiene como protagonista al dios Apolo, se puede diferenciar, en la figura de la divinidad, un narrador secundario cuando el poeta transcribe su discurso directo. En la misma sección, a continuación, y como respuesta a su relato, interviene un tercer narrador, Quirón, quien en su discurso tiene la responsabilidad de transmitir la profecía que consagrará un origen glorioso para la ciudad del vencedor. Las implicancias mutuas entre los narradores y sus respectivos relatos quedan engarzados en el marco estructural del conjunto de la composición, a partir de un leitmotiv que vertebra la obra de inicio a fin: el motivo del

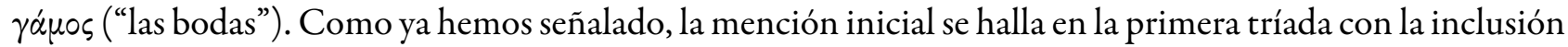
del mito de Apolo y Cirene, en el pasado mítico; en la segunda historia incluida, la temática reaparece de la mano de Anteo, quien elige a Dánao como modelo para acordar bodas para su hija. En medio de ambas narraciones, para destacar su lugar en la composición, Píndaro, sorprendentemente, retoma el tópico y lo asocia a Telesícrates, en un lanzamiento hacia el futuro, cuando enaltece su figura al aseverar que fue testigo de que, ante otros triunfos del vencedor, las mujeres rogaban que fuera su amadísimo esposo o su hijo (vv. 98-100), como ya hemos señalado.

En cuanto al manejo del tiempo, el poeta glorifica el momento del canto a partir del diálogo fluido con un pasado mítico remoto y prestigioso, mientras que un impulso hacia el futuro garantiza fama y notoriedad para el vencedor y su tierra. Como afirma Verde Castro (2009, p. 171): "hay una dinámica en la composición en anillo que se manifiesta en un movimiento pendular de la periferia hacia el centro y viceversa, y que implica un desplazamiento en el tiempo y el espacio. Cada una de las instancias temporales se duplica en un juego de interrelaciones y correspondencias complejo que da cuenta de la composición en anillo", típica de la poética pindárica. El presente de la performance conserva su equivalente en el momento de la competencia. "Para que se advierta claramente la incursión en el pasado, es forzoso acentuar el presente como punto de arranque" - destaca Verde Castro (2009, p. 171). Si bien el triunfo del atleta ha sido anterior a la representación, la ceremonia festiva le otorga entidad (por el carácter performativo del lenguaje) en este recibimiento organizado en su ciudad natal. La inserción del pasado del mito colabora en relación directa con el camino hacia ese futuro de fama y $x \lambda \varepsilon$ źoఢ. Del mismo modo, hemos observado ese juego de idas y vueltas 
temporales en los mitos incluidos; analepsis y prolepsis coadyuvan a engrandecer la ciudad y la hazaña del vencedor que infunde en la comunidad confianza en un futuro aún más próspero.

A su vez, estos quehaceres del presente guardan su correlato en la coordenada espacial. El atleta, oriundo de Cirene, ciudad en que se lleva a cabo la performance, ha competido y triunfado en Delfos y regresa a Libia,

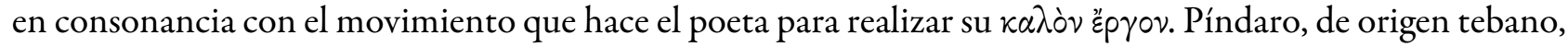
se traslada a Cirene para cumplir con el trabajo que se le ha encargado.

Paralelamente, en el nivel del mito, las dos narraciones desarrolladas presentan correspondencia tanto en el manejo de la temporalidad cuanto en los recorridos por los diferentes espacios. Mientras que en el mito de Apolo y Cirene los personajes parten de Tesalia hacia Libia, solo los personajes del relato local permanecerán en aquella tierra africana: Alexidamo y la hija de Anteo. En la historia incluida de Dánao, personaje oriundo de Libia, el movimiento será el inverso, desde África se dirigirá hacia Argos, y allí se establecerá y buscará esposos para sus hijas. En la dimensión espacial, la leyenda local otorga pleno protagonismo a la ciudad de Telesícrates. Finalmente, la ciudad de la que proviene el poeta, Tebas, ofrece la excusa perfecta para asociar brevemente el mito de Heracles y ratificar la fama y reputación del artífice del canto.

Tiempo y espacio de la performance, en constante diálogo con las coordenadas de la ocasión del epinicio y de las narraciones míticas, revelan la maestría de uno de los más exquisitos poetas líricos de la Antigüedad. La belleza de la composición, solemne y cálida, habla por sí misma (Fränkel, 1993, p. 418).

\section{REFERENCIAS}

Burton, R.W.B. (1962). Pindar's Pythian Odes. Oxford: University Press.

Currie, B.G.F. (2012). Pindar and Bacchylides. En I. De Jong (Ed.) Space in Ancient Greek Literature. Studies in Ancient Greek Narrative (Vol III, pp. 285-303). Leiden: Brill.

Farnell, L.R. (1961). Pindar. A Commentary. Amsterdam: Hakkert.

Fränkel, H. (1993). Poesía y Filosofía de la Grecia Arcaica. Madrid: Visor.

Grimal, P. (1981, $5^{\circ}$ reimp.). Diccionario de Mitología Griega y Romana. Barcelona: Paidós.

Hamamé, G.N. (2019). La Pítica IX de Píndaro. En M. I. Saravia de Grossi (coord.) Pindaro. Poeta de luces y sombras (pp. 45-72). Recuperado de http://sedici.unlp.edu.ar/handle/10915/83284

Lamari, A. (2010). Narrative, intertext, and Space in Euripides' Phoenissae. Berlin, New York: De Gruyter

Pfeijffer, I. L. (2004). Pindar and Bacchylides. En I. De Jong, R. Nünlist and A. Bowie (Eds.), Narrators, Narratees, and Narratives in Ancient Greek Literature. Studies in Ancient Greek Narrative (Vol I, pp. 213-232). Leiden: Brill.

Míguez Barciela, A. (2016). Píndaro y la "verdad” del poema. Synthesis, 23, 29-38.

Nünlist, R. (2012). Pindar and Bacchylides. En I. De Jong \& R. Nünlist (Eds.), Time in Ancient Greek Literature. Studies in Ancient Greek Narrative (Vol. II, pp. 233-251). Leiden : Brill.

Ortega, A. (1984). Pindaro. Odas y Fragmentos. Madrid: Gredos.

Pindar (1937). The Odes of Pindar. Cambridge: Harvard University Press. Recuperado de http://www.perseus.tufts .edu/hopper/

Puech, A. (1951). Pindare. Paris: Les Belles Lettres.

Slater, W.J. (1969). Lexicon to Pindar. Berlín: De Gruyter.

Saravia de Grossi, M. I. (coord.) (2019). Pindaro. Poeta de luces y sombras. Recuperado de http://sedici.unlp.edu.ar/ handle/10915/83284

Verde Castro, C. V. (2009). El encuadre de la Pítica IV de Píndaro. Synthesis, 16, 167-216.

\section{Notas}

1 Lamari (2010). 
2 Para ver la estructura compositiva y algunos aspectos precisos de la obra, cf. Hamamé (2019).

3 Cf. Míguez Barciela (2016, pp.31-33) quien se detiene a establecer las diferencias entre el propósito del relato en Píndaro y en el resto de los géneros literarios como en la epopeya o el drama.

4 Cf. Saravia de Grossi (2019, p. 8).

5 Cf. Saravia de Grossi (2019, 9-10).

6 En todos los casos, la traducción del texto griego nos pertenece.

7 Cf. Burton (1962, p. 36).

8 Libia, región del norte de África que, a la altura de Europa y Asia, constituiría un tercer continente. Sobre la teoría de las tres partes del mundo, este resulta el más antiguo testimonio. Cf. Fränkel (1993, p. 411), especialmente nota 34.

9 Este adverbio remonta al nacimiento de Creusa, madre de Hipseo, padre de Cirene, nieto de Poseidón y rey de los Lapitas. En su trabajo sobre la Pítica IV, Verde Casto (2016, pp. 180-181) destaca el recurrente manejo de adverbios temporales en este mismo sentido.

10 En este punto resulta interesante el análisis de Burton (1962, pp. 40-41).

11 Cf. Farnell (1961, p. 201).

12 Para un análisis de la función de las gnômai en los poemas de Píndaro, cf. Míguez Barciela (2016) quien considera que dichas aseveraciones a las que prefiere denominar "paremias" constituyen una de las formas de las que se vale el poeta para romper, en sus epinicios, la ilusión mimética característica del decir poético.

\section{BY-NC-SA}

